\title{
Calcium signaling in skeletal muscle development, maintenance and regeneration
}

Michelle K. Tu, Jacqueline B. Levin, Andrew M. Hamilton, Laura N. Borodinsky

Department of Physiology and Membrane Biology and Shriners Hospital for Children Northern California, University of California Davis, Sacramento CA 95817.

Corresponding author

LAURA N. BORODINSKY

DEPARTMENT OF PHYSIOLOGY \& MEMBRANE BIOLOGY AND SHRINERS

HOSPITAL FOR CHILDREN NORTHERN CALIFORNIA, UNIVERSITY OF CALIFORNIA DAVIS SChOOL OF Medicine, 2425 StOCKTON BlVD, SACRAMENTO, CA 95817.

PHONE: 916-453-2285

FAX: 916-453-2288

E-MAIL: LNBORODINSKY@UCDAVIS.EDU 


\begin{abstract}
Skeletal muscle-specific stem cells are pivotal for tissue development and regeneration. Muscle plasticity, inherent in these processes, is also essential for daily life activities. Great advances and efforts have been made in understanding the function of the skeletal muscle-dedicated stem cells, called muscle satellite cells, and the specific signaling mechanisms that activate them for recruitment in the repair of the injured muscle. Elucidating these signaling mechanisms may contribute to devising therapies for muscular injury or disease. Here we review the studies that have contributed to our understanding of how calcium signaling regulates skeletal muscle development, homeostasis and regeneration, with a focus on the calcium dynamics and calciumdependent effectors that participate in these processes.
\end{abstract}




\section{Introduction.}

Throughout tissue morphogenesis and homeostasis, stem cells are recruited to generate the necessary tissue mass, to enable plastic changes in tissue size when challenged by changing stimuli, and to replenish damaged or degenerated tissue. $\mathrm{Ca}^{2+}$ is a ubiquitous intracellular signal that regulates a myriad of cellular processes. Skeletal muscle formation and plasticity presents an excellent model system for the study of the role of $\mathrm{Ca}^{2+}$ signaling due to the fact that $\mathrm{Ca}^{2+}$ dynamics are essential for muscle function. While the tight coupling of muscle excitation and contraction by $\mathrm{Ca}^{2+}$ dynamics has been well established, comparatively little is known about the role of $\mathrm{Ca}^{2+}$ dynamics in muscle formation, growth and regeneration. Because all these physiological contexts recruit stem cells, the investigation of muscle stem cell $\mathrm{Ca}^{2+}$ physiology becomes crucial for the elucidation of $\mathrm{Ca}^{2+}$ signaling-dependent regulation of skeletal muscle dynamics.

Myogenesis occurs during embryonic development through the proliferation and differentiation of dedicated progenitors in the somites. These cells initially express the transcription factors Pax3 and Pax7, but lose this expression during progressive specialization through the expression of a family of myogenic regulatory factors (MRFs), which include Myf5, MyoD, myogenin and MRF4 [1, 2]. Skeletal muscle formation continues with the differentiation of these specialized progenitors to form muscle fibers. A subset of the myogenic progenitors does not proceed through this specialization, retains Pax3/Pax7 expression and remains quiescent in the maturing and adult skeletal muscle. These muscle-specific stem cells are called muscle satellite cells $[2,3]$.

The participation of muscle satellite cells in skeletal muscle homeostasis has been a matter of debate, although robust evidence supports the role of satellite cells in muscle regeneration [4]. Inhibition of the muscle growth inhibitors myostatin and activin A by knocking out their receptor Acvr2 from myofibers in mice deficient in muscle satellite cells induces muscle hypertrophy, without satellite cell proliferation or an increase in nuclei number in myofibers [5]. This suggests that satellite cells may not play an essential role in muscle hypertrophy. In contrast, depletion of Pax7-expressing cells from the adult injured muscle blocks muscle regeneration [6-9], indicating the indispensable function of muscle satellite cells for muscle regeneration. The different roles of skeletal muscle stem cells in muscle development, growth and regeneration may originate from distinct physiological profiles of muscle stem cells in the different contexts. Identifying conserved and distinct mechanisms among myogenesis, muscle homeostasis and regeneration may be relevant to devising effective therapies for the injured and dystrophic skeletal muscle.

Here we review the role of $\mathrm{Ca}^{2+}$-mediated activity in myogenesis, skeletal muscle plasticity and regeneration.

\section{Calcium signaling in skeletal muscle development}

Skeletal muscle development progresses through several stages by which muscle progenitor cells become mature muscle fibers. Although different species proceed through distinct cellular events, they all share a common program consisting of the proliferation of mesodermal stem cells, then the progressive specialization into skeletal 
muscle progenitors, followed by the differentiation of muscle cells and further specification into different muscle cell types (Figure 1). This sequence of events finishes with the spatial arrangement of cells to form the functional musculature [2, 10-12]. Finally muscle cells undergo two rounds of fusion, first into multinucleated nascent myotubes and second into myofibers [13-16].

The role of $\mathrm{Ca}^{2+}$ signaling has been considered in each of these developmental steps and clear evidence of the necessity for different aspects of $\mathrm{Ca}^{2+}$ signaling has emerged in a broad spectrum of species, including the invertebrates Caenorhabditis elegans and Drosophila melanogaster, the lower vertebrates Xenopus laevis and zebrafish and in mammals such as mice and humans. The identified molecular mechanisms underlying $\mathrm{Ca}^{2+}$ participation in muscle development are responsible for either shaping $\mathrm{Ca}^{2+}$ dynamics or for transducing $\mathrm{Ca}^{2+}$ signals into a cellular response. $\mathrm{Ca}^{2+}$ stores are pivotal for eliciting a precise spatiotemporal pattern of $\mathrm{Ca}^{2+}$ signal in developing muscle cells. Expression of inositol-triphosphate receptors (IP3R) and ryanodine receptors (RyR) is developmentally regulated in mouse [17] and frog embryos [18], suggesting critical roles at different stages of muscle morphogenesis. Indeed, inhibiting $\mathrm{Ca}^{2+}$ transients in Xenopus laevis embryos disrupts skeletal muscle development by interfering with myofibril organization and sarcomere assembly [19]. In addition, inhibiting the $\mathrm{Ca}^{2+} /$ Calmodulin (CaM)-dependent myosin light chain kinase by interfering pharmacologically with its kinase activity or by incubating with a peptide pseudosubstrate impairs myosin thick filament assembly [20], implying a potential mechanism for RyR-Ca ${ }^{2+}$-driven muscle development. RyR1 homozygous mutant mice in which RyR-mediated $\mathrm{Ca}^{2+}$ release is abolished die perinatally and also exhibit a severely disrupted musculature with small myotubes and disarranged myofibrils [21]. Altogether, these findings demonstrate a universal requirement for RyR-mediated $\mathrm{Ca}^{2+}$ dynamics in skeletal myogenesis. In addition, human myoblast differentiation in vitro is regulated by intracellular $\mathrm{Ca}^{2+}$ increases induced by changes in membrane potential [2224]. Xenopus embryonic myocytes exhibit two types of $\mathrm{Ca}^{2+}$ transients, both RyRdependent, but of different durations [25]. The long-duration transients that last on average 80 seconds are present during a restricted developmental window prior to formation of myofibrils, while short 2-second-long transients persist during sarcomere assembly. Interestingly, artificial extension of long transient production inhibits sarcomere assembly [25], suggesting that the spatiotemporal code contained in the $\mathrm{Ca}^{2+}$ dynamics of differentiating muscle cells is critical for muscle development.

Directly linked to the pattern of $\mathrm{Ca}^{2+}$ dynamics in developing muscle cells is the storeoperated calcium entry (SOCE) orchestrated by the sensor of internal $\mathrm{Ca}^{2+}$ stores, stromal interaction molecule 1 (STIM1), and the SOCE channels Orai1 and Transient Receptor Potential Canonical (TRPC) channels. STIM1 expression is developmentally regulated, peaking postnatally in the developing muscle in mice [26]. Mice lacking functional STIM1 die perinatally from a skeletal myopathy [27], indicating that STIM1-dependent $\mathrm{Ca}^{2+}$ signaling is necessary for myogenesis. Moreover, sarcolipin, an inhibitor of the sarcomere reticulum $\mathrm{Ca}^{2+}$ pump that opposes STIM1 action, is highly expressed in the embryonic muscle and is markedly increased in the muscle of loss-of-function mutant STIM1 mice suggesting that sarcolipin and STIM1 govern SOCE during myogenesis [26]. Expression of TRPC1 is also developmentally regulated increasing at the beginning 
of differentiation, and is necessary for myoblast migration and fusion into myotubes [28]. Moreover, in myoblasts TRPC1 constitutes an essential stretch-activated channel modulated by sphingosine 1-phosphate, a bioactive lipid involved in satellite cell biology and myogenesis [29]. These studies serve to highlight the importance of controlling $\mathrm{Ca}^{2+}$ dynamics to proper muscle development.

A number of signaling elements immediately downstream of $\mathrm{Ca}^{2+}$ signal are demonstrably vital to normal muscle development. The candidate effectors that account for the importance of $\mathrm{Ca}^{2+}$ signaling in myogenesis comprise the CaM-dependent kinases and phosphatases, mitogen-activated protein kinases (MAPKs) and $\mathrm{Ca}^{2+}$-sensitive transcription factors including the nuclear factor of activated T cells (NFATc). $\mathrm{Ca}^{2+}-$ calmodulin-dependent protein kinase (CaMK) signaling prevents formation of histone deacetylase-myocyte enhancer factor 2 (HDAC-MEF2) complexes [30, 31], thereby releasing MEF2 myogenic transcriptional activity [30, 32, 33], which otherwise is repressed by HDAC4 and 5 nuclear export [34].

The role of the CaM-dependent phosphatase, calcineurin, in mouse myogenesis starts with its function in early skeletal muscle cell differentiation $[35,36]$ by regulating expression of transcription factors MEF2, MyoD and myogenin [35-37]. In Drosophila, the role of calcineurin in muscle development is also apparent; mutants for the regulatory subunit of calcineurin exhibit severe defects in flight muscle organization [38]. Additionally, calcineurin is involved in further muscle cell specialization, promoting differentiation of slow fibers in vitro and in vivo by recruiting the transcription factor NFATc [39-43]. Calcineurin dephosphorylates NFATc, promoting its translocation to the nucleus for the upregulation of target genes [37, 44, 45]. Knockout mice for different NFATc isoforms revealed that these variants contribute to distinct aspects of muscle development and function. NFATc3 knockout mice present with reduced muscle mass and number of fibers but appropriate organization of the existing fibers, demonstrating a role for NFATc3 in early stages of primary myogenesis [46]. In contrast, mice lacking NFATc2 present a normal number of formed fibers but are deficient in myoblast fusion resulting in significantly fewer nuclei per fiber [47, 48], demonstrating a dual role for NFATc in both formation and organization of musculature.

In addition to the classic CaM-dependent pathways, other signaling cascades may contribute to the transduction of $\mathrm{Ca}^{2+}$ dynamics-driven skeletal muscle development. Signaling through several elements of the MAPK pathway regulates different steps of myogenesis [49-51]. Erk2 promotes muscle progenitor proliferation by upregulating cyclin D1 expression [49]. Subsequently, MAPK p38 activity is induced during differentiation of L8 myoblasts. Inhibiting p38 impairs myogenesis shown by reduced expression of MyoD in Xenopus embryos and of MEF2 factors in L8 cells [50, 51]. Because MAPKs interact with $\mathrm{Ca}^{2+}$ signaling [52] in the developing spinal cord [53] and, importantly, in the skeletal muscle [54], they may jointly coordinate regulation of skeletal muscle development (Figure 2).

\section{Calcium signaling in skeletal muscle growth and maintenance}


Once the skeletal muscle is formed during development, its size, performance and overall physiology remain plastic and the tissue responds to the changing surroundings (Figure 1). Skeletal muscle growth is based on further formation of large multinucleated muscle cells. After birth the tissue is subjected to an intense period of growth and differentiation coordinated by multiple signaling pathways. Some aspects of the cellular and molecular mechanisms responsible for the regulation of skeletal muscle growth are known and widely accepted but others remain unknown or controversial. Many of the myogenic factors that operate during embryonic development are also recruited for the growth of mature or maturing skeletal muscle, but myogenesis and plasticity are distinguished by different intrinsic and extrinsic environments and distinct competencies of cells. Here we will discuss signaling factors that are important in skeletal muscle growth and maintenance and the role of $\mathrm{Ca}^{2+}$ in their regulation.

The Insulin-like Growth Factor 1 (IGF-1) recruits the phosphoinositide 3-kinasemammalian target of rapamycin (PI3-K/Akt/mTOR) signaling axis to implement muscle hypertrophy [55-57]. Whether the IGF-1-triggered pathway also recruits $\mathrm{Ca}^{2+}$ signaling to promote skeletal muscle growth, and in particular the calcineurin/NFAT signaling axis, has been a matter of debate. Some studies show that overexpressing calcineurin is sufficient to induce hypertrophy of soleus muscle fibers [58] and transgenic mice expressing either a null mutation for calcineurin $\mathrm{A} \beta$ or muscle-specific overexpression of the calcineurin inhibitor MCIP1 exhibit reduced fiber size [59, 60], demonstrating a role for calcineurin in hypertrophy. In contrast, mice with either global or muscle-specific calcineurin depletion subjected to muscle hypertrophic growth by mechanical overload or IGF-1 stimulation do not show defects in muscle growth [61]. Nevertheless, these mice did show impairment in overload-mediated fiber-type switching [61]. These studies suggest that calcineurin is important for muscle growth and remodeling, however different animal models may lead to different levels of perturbation of calcineurin action and diverse compensatory mechanisms associated with the experimental approach. Importantly, insulin and IGF-1 induce $\mathrm{Ca}^{2+}$ dynamics through both $\mathrm{Ca}^{2+}$ influx and release from IP3R and RyR-operated stores [62-64]. Moreover, another hormone-like signaling molecule, prostaglandin $\mathrm{F} 2 \alpha$, increases intracellular $\mathrm{Ca}^{2+}$ concentration, activating NFATc2 and inducing muscle cell growth and nuclear accretion [65]. These studies suggest that molecularly diverse stimuli may converge at recruiting $\mathrm{Ca}^{2+}$ signaling to implement muscle growth (Figure 2).

Another experimental paradigm for studying muscle plasticity is the imposition of cyclic stretch in cultured muscle satellite cells. This activates $\mathrm{Ca}^{2+}$ influx through the mechanosensitive cation channel and the long-lasting-type voltage-gated $\mathrm{Ca}^{2+}$ channel [29, 66, 67]. Inhibiting these channels prevents muscle satellite cell activation and proliferation triggered by the mechanical stimulus [67], suggesting that $\mathrm{Ca}^{2+}$ dynamics are necessary for the mechanosensing response of muscle satellite cells. Stretch also activates the ras-MEK-extracellular signal-regulated kinase (ERK) signaling pathway through the recruitment of phospholipase A2, which may interact with the stretch mechanoreceptors [68]. The integration of signaling pathways is given by the stimulusdriven, $\mathrm{Ca}^{2+}$-dependent phosphorylation of ERK and CREB, which results in the upregulation of early genes c-fos, c-jun, and egr-1 [69]. In turn, a timely targeted gene expression is required for long-term changes in muscle strength during physical training. 
Exercise also induces switching from fast-twitch to slow-twitch fibers, which is mediated by PKD [70]. This kinase phosphorylates class IIa HDACs, releasing their inhibition of MEF2, leading to transcriptional activation of myosin heavy chain genes that enables muscle fiber type transformation [71]. Moreover, disrupting expression of myostatin in mice results in a switch in muscle fiber type from slow to fast, in addition to muscle growth by recruiting the non-canonical, $\mathrm{Ca}^{2+}$-dependent Wnt pathway [72]. This may be triggered by a change in $\mathrm{Ca}^{2+}$ dynamics as a consequence of the reduction in sarcoplasmic $\mathrm{Ca}^{2+}$ release [73].

The precise dynamics of intracellular $\mathrm{Ca}^{2+}$ levels in muscle cells are crucial for specifying the stimuli-driven changes in muscle growth and performance through the coordination of $\mathrm{Ca}^{2+}$ influx and release from stores. Orail promotes growth and limits fatigue in adult skeletal muscle, while dominant negative Orail mice show increased susceptibility to fatigue [74]. Additionally, the burst of muscle growth and differentiation that occurs after birth in mice is dependent on the $\mathrm{Ca}^{2+}$ signaling regulated by STIM1 [75]. Excitation-contraction coupling is normal in mice lacking STIM1 from the skeletal muscle. However, muscle fibers of neonatal $\mathrm{mSTIM}^{-/-}$mice fail to elicit $\mathrm{Ca}^{2+}$ transients evoked by tonic neurostimulation, resulting in inhibition of calcineurin, MAPKs, ERK1/2, and AKT signaling pathways. This suggests that the interaction between STIM1 and SOCE is necessary for neonatal muscle growth and differentiation [75]. An additional pathway that may participate in $\mathrm{Ca}^{2+}$-induced muscle plasticity is $\mathrm{CaMKK}$ which, when constitutively activated, promotes muscle growth by recruiting mTORC1 signaling and promotion of protein synthesis [76].

Another relevant aspect of muscle homeostasis is the limitation to growth and performance experienced during aging. Aging is accompanied by active muscle wasting through mechanisms that are not fully understood, but correlate with age-dependent changes in $\mathrm{Ca}^{2+}$ dynamics. Evidence for a relationship between $\mathrm{Ca}^{2+}$ signaling and aging muscle comes from studies on $\mathrm{Ca}^{2+}$ sparks, which consist on focalized $\mathrm{Ca}^{2+}$ release from the sarcoplasmic reticulum. In the young muscle $\mathrm{Ca}^{2+}$ sparks are not apparent at rest but are activated upon membrane deformation due to mechanical stimulation or osmotic stress $[77,78]$. In contrast, in the aged skeletal muscle, the $\mathrm{Ca}^{2+}$ spark response is altered and there seems to be a segregated intracellular $\mathrm{Ca}^{2+}$ reserve that cannot be recruited by voltage-induced $\mathrm{Ca}^{2+}$ release, uncoupling $\mathrm{Ca}^{2+}$ dynamics from the excitation-contraction process [79]. This alteration in $\mathrm{Ca}^{2+}$ dynamics precedes muscle wasting and correlates with downregulation of mitsugumin-29 expression, a synaptophysin-related membrane protein important for muscle structure and function and $\mathrm{Ca}^{2+}$ homeostasis [79]. SOCE is also affected in the muscle of aged mice, presumably due to downregulation of mitsugumin-29 expression [80]. This protein interacts with TRPC3 [81, 82] and RyR1 and regulates apoptosis [83], providing a potential link between $\mathrm{Ca}^{2+}$ signaling and control of muscle homeostasis.

Muscle wasting is not exclusive to aging, but is shared by many physiological and pathological conditions. In metastatic cancer concurring with bone destruction, secreted transforming growth factor- $\beta$ (TGF- $\beta$ ) induces excessive oxidation of RyR1, resulting in leaky channels that interfere with $\mathrm{Ca}^{2+}$ signaling and muscle contraction. Preventing RyR leakage improves muscle function, suggesting that muscle weakness induced by pathological TGF- $\beta$ signaling is due to decreased $\mathrm{Ca}^{2+}$-induced muscle force production 
[84]. $\mathrm{Ca}^{2+}$ sparks induced by membrane deformation and exercise in the young healthy muscle, which are decoupled in the aged muscle as mentioned above, are also deregulated and sustained irreversibly in the dystrophic muscle [78]. In a mouse model of muscular dystrophy, increased sarcolemma localization of a TRP channel, the growth factor-regulated channel, which results in $\mathrm{Ca}^{2+}$ overload in response to stretch, leads to muscle cell degeneration [85].

Skeletal muscle homeostasis relies on spatiotemporally regulated $\mathrm{Ca}^{2+}$ signaling in the different cell types involved in muscle plasticity. Aging and disease disables muscle homeostasis due to loss of the regulatory mechanisms dependent on appropriate $\mathrm{Ca}^{2+}$ dynamics.

\section{Calcium signaling in muscle regeneration}

Tissue regeneration involves a tightly orchestrated sequence of cellular events consisting of cell proliferation, migration, and differentiation, culminating in integration of cells into functional regenerating tissues. These cellular events are similar to the processes that occur during development (Figure 1) raising the question of whether the $\mathrm{Ca}^{2+}$ signalingmediated mechanisms of muscle development are apparent in muscle regeneration.

In our recent study we found that spontaneous $\mathrm{Ca}^{2+}$ transients manifest in the early stages of muscle regeneration and that perturbing $\mathrm{Ca}^{2+}$ release from internal stores impairs the regenerative process. We discovered that muscle cells from the regenerating Xenopus laevis tail exhibit spontaneous $\mathrm{Ca}^{2+}$ transients during the first hours post injury [86]. Incubation of regenerating tadpoles with ryanodine, which abolishes $\mathrm{Ca}^{2+}$ transients in regenerating muscle cells, leads to a reduction in the number of muscle progenitor cells and activated muscle satellite cells in the regenerating tissue [86]. Muscle satellite cells are the major cell type that contributes to muscle repair and regeneration. When muscle is injured, activated muscle satellite cells proliferate and differentiate into skeletal muscle cells, giving rise to new tissue $[87,88]$. Our findings suggest that perturbing $\mathrm{Ca}^{2+}$ release from RyR-operated stores interferes with the early phases of muscle regeneration, and that this $\mathrm{Ca}^{2+}$ activity is necessary for activation and proliferation of muscle satellite cells (Figure 2). In addition to RyR, release of $\mathrm{Ca}^{2+}$ from intracellular stores can be mediated by IP3R. Recently, investigators have determined that $\mathrm{Ca}^{2+}$ release mediated by IP3R type 1 is essential during the early steps of human myoblast differentiation [89], however our study found that $\mathrm{Ca}^{2+}$ transients in injured muscle were not IP3R-mediated and that IP3R function was not necessary for muscle regeneration [86], suggesting that muscle regeneration is mechanistically distinct from muscle development.

Unlike the dispensability of IP3R activation for muscle replenishment in injured tadpoles, regeneration of other tissues depends on IP3R-mediated signaling. For example, inhibition of IP3R expression in hepatocytes leads to a reduction in hepatocyte proliferation and delayed liver regeneration [90], showing its necessity for the early phases of repair. Another tissue in which $\mathrm{Ca}^{2+}$ activity is vital for development and regeneration is the skin. Proliferating keratinocytes of the epidermis facilitate adult skin homeostasis and participate in the wound healing process following injury [91-93]. $\mathrm{Ca}^{2+}$ 
is a key regulator in both keratinocyte differentiation and proliferation. At low intracellular $\mathrm{Ca}^{2+}$ levels, keratinocytes retain proliferative activity. At higher $\mathrm{Ca}^{2+}$ concentrations, proliferative activity is suppressed and keratinocytes express differentiation markers [94]. $\mathrm{Ca}^{2+}$ is also necessary in driving migration of basal keratinocytes. Loss of Orail results in inhibited directional migration of keratinocytes [95]. Moreover, expression of RyRs in human keratinocytes has been linked to keratinocyte differentiation and epidermal barrier homeostasis [96]. Application of a RyR agonist or antagonist delays or enhances skin barrier recovery respectively [96]. Further studies will help determine whether the importance of $\mathrm{Ca}^{2+}$ activity in regeneration is universal and will identify the particular $\mathrm{Ca}^{2+}$ dynamics that facilitate regeneration in different tissues. Other sources of $\mathrm{Ca}^{2+}$ response in activated muscle satellite cells during regeneration are the TRPCs. In cultured mouse muscle fibers hosting satellite cells the addition of fibroblast growth factor- 2 induces an increase in intracellular $\mathrm{Ca}^{2+}$ levels in activated muscle satellite cells through TRPCs [97]. Full elucidation of the molecular mechanisms regulating $\mathrm{Ca}^{2+}$ dynamics in the activation of muscle satellite cells upon injury requires further investigation.

The downstream candidates recruited by $\mathrm{Ca}^{2+}$ activity during muscle regeneration are numerous (Figure 2), given the crosstalk nature of $\mathrm{Ca}^{2+}$ signaling. A central effector of $\mathrm{Ca}^{2+}$ dynamics, calcineurin, is expressed in activated and proliferating muscle satellite cells four days after injury in rodent leg muscles, while it is absent in quiescent counterparts [98]. Moreover, inhibiting calcineurin by injecting injured mice with cyclosporine impairs regeneration and leads to muscle fiber atrophy [98], suggesting a role for calcineurin in skeletal muscle repair. In addition, enhancing calcineurin activity by expressing a constitutively active form in a model of muscle injury in mice enhances structural and functional muscle regeneration, presumably through upregulation of the expression of myogenic genes like MEF-2 and myogenin [99]. In turn, calcineurin activity is tightly regulated by several modulatory proteins [100, 101] including myosporin, a scaffolding protein localized to the Z-disc/costamere region of striated muscle that inhibits calcineurin activity, prevents the slow fiber type switch normally associated with calcineurin action, and impairs regeneration of the injured muscle [102].

Another class of $\mathrm{Ca}^{2+}$-dependent phosphatases, calpains, also contributes to the control of muscle satellite cell activation [103]. Muscle satellite cells express m-calpain in a cell cycle-dependent manner, with m-calpain primarily localized to the cytoplasm in nonproliferating satellite cells. Upon injury, however, m-calpain localizes in the satellite cell nucleus. When m-calpain is inhibited, satellite cells show defects in cell cycle control. These defects lead to prevention of Myo-D accumulation in the nucleus and enhancement of Myf5 expression, subsequently impairing satellite cell function and the early stages of muscle regeneration [103].

$\mathrm{Ca}^{2+}$ signaling participation in skeletal muscle regeneration has become increasingly clear. However, further investigation is necessary to identify the $\mathrm{Ca}^{2+}$ dynamics specific to each type of cell participating in the repair and regeneration of the skeletal muscle. We also anticipate that elucidating the intra and intercellular signaling within the regenerating muscle and with adjacent and supporting tissues will prove important. The progressive loss of the muscle regenerative capacity with age indicates that some signaling mechanisms present in development are no longer available in the aging muscle. Indeed, 
the satellite cells of aged, injured muscle exhibit insufficient upregulation of the Notch ligand Delta, which is necessary for proliferative expansion of myogenic progenitors and muscle regeneration [104]. Interestingly, the crosstalk between Notch and Wnt signaling pathways is necessary for a temporal balance between myogenic progenitor proliferation and differentiation in adult myogenesis [105], while activation of the canonical Wnt signaling pathway in aged progenitors favors differentiation towards the fibrogenic instead of myogenic lineage, leading to tissue fibrosis and poor muscle regeneration [106]. A pivotal role for $\mathrm{Ca}^{2+}$ signaling is expected considering that it modulates both the Notch [107] and Wnt [108, 109] signaling pathways.

\section{Concluding remarks}

In this review we have discussed evidence that $\mathrm{Ca}^{2+}$ is an important component of the signaling promoting muscle formation, muscle homeostasis, and regeneration. In particular, $\mathrm{Ca}^{2+}$ changes may direct muscle satellite cells to maintain their quiescent state, proliferate, or differentiate into functional muscle. A full understanding of muscle satellite cell physiology is crucial to devising appropriate therapies to promote muscle regeneration and prevent muscle wasting in aging and disease. The spatiotemporal changes in $\mathrm{Ca}^{2+}$ dynamics and their signaling partners in muscle satellite cells of both young and aged tissue in response to external demands await further investigation.

\section{Conflict of interest}

None

\section{Acknowledgements}

Research in the lab has been supported by the Basil O'Connor Starter Scholar Research Award Grant 5-FY09-131 from the March of Dimes Foundation, Klingenstein Foundation Award in Neuroscience, NSF 1120796, NIH-NINDS R01NS073055 and Shriners Hospital for Children 86500-NCA and 85220-NCA grants, by a doctoral fellowship from the California Institute for Regenerative Medicine-UC Davis training program to MKT and by a postdoctoral fellowship from Shriners Hospital for Children to $\mathrm{AMH}$. 


\section{References}

[1] C.F. Bentzinger, Y.X. Wang, M.A. Rudnicki, Building muscle: molecular regulation of myogenesis, Cold Spring Harbor perspectives in biology, 4 (2012).

[2] N.A. Dumont, Y.X. Wang, M.A. Rudnicki, Intrinsic and extrinsic mechanisms regulating satellite cell function, Development, 142 (2015) 1572-1581.

[3] A. Mauro, Satellite cell of skeletal muscle fibers, The Journal of biophysical and biochemical cytology, 9 (1961) 493-495.

[4] F. Relaix, P.S. Zammit, Satellite cells are essential for skeletal muscle regeneration: the cell on the edge returns centre stage, Development, 139 (2012) 2845-2856.

[5] S.J. Lee, T.V. Huynh, Y.S. Lee, S.M. Sebald, S.A. Wilcox-Adelman, N. Iwamori, C. Lepper, M.M. Matzuk, C.M. Fan, Role of satellite cells versus myofibers in muscle hypertrophy induced by inhibition of the myostatin/activin signaling pathway, Proceedings of the National Academy of Sciences of the United States of America, 109 (2012) E2353-2360.

[6] S. Gunther, J. Kim, S. Kostin, C. Lepper, C.M. Fan, T. Braun, Myf5-positive satellite cells contribute to Pax7-dependent long-term maintenance of adult muscle stem cells, Cell stem cell, 13 (2013) 590-601.

[7] C. Lepper, T.A. Partridge, C.M. Fan, An absolute requirement for Pax7-positive satellite cells in acute injury-induced skeletal muscle regeneration, Development, 138 (2011) 3639-3646.

[8] R. Sambasivan, R. Yao, A. Kissenpfennig, L. Van Wittenberghe, A. Paldi, B. Gayraud-Morel, H. Guenou, B. Malissen, S. Tajbakhsh, A. Galy, Pax7-expressing satellite cells are indispensable for adult skeletal muscle regeneration, Development, 138 (2011) 3647-3656.

[9] J. von Maltzahn, A.E. Jones, R.J. Parks, M.A. Rudnicki, Pax7 is critical for the normal function of satellite cells in adult skeletal muscle, Proceedings of the National Academy of Sciences of the United States of America, 110 (2013) 16474-16479.

[10] M. Buckingham, F. Relaix, PAX3 and PAX7 as upstream regulators of myogenesis, Seminars in cell \& developmental biology, (2015).

[11] P. Bailey, T. Holowacz, A.B. Lassar, The origin of skeletal muscle stem cells in the embryo and the adult, Current opinion in cell biology, 13 (2001) 679-689.

[12] M. Buckingham, S.D. Vincent, Distinct and dynamic myogenic populations in the vertebrate embryo, Current opinion in genetics \& development, 19 (2009) 444-453. [13] S.M. Hindi, M.M. Tajrishi, A. Kumar, Signaling mechanisms in mammalian myoblast fusion, Science signaling, 6 (2013) re2.

[14] E.H. Chen, E.N. Olson, Towards a molecular pathway for myoblast fusion in Drosophila, Trends in cell biology, 14 (2004) 452-460.

[15] R.K. Ho, E.E. Ball, C.S. Goodman, Muscle pioneers: large mesodermal cells that erect a scaffold for developing muscles and motoneurones in grasshopper embryos, Nature, 301 (1983) 66-69.

[16] E. Rushton, R. Drysdale, S.M. Abmayr, A.M. Michelson, M. Bate, Mutations in a novel gene, myoblast city, provide evidence in support of the founder cell hypothesis for Drosophila muscle development, Development, 121 (1995) 1979-1988. 
[17] N. Rosemblit, M.C. Moschella, E. Ondriasa, D.E. Gutstein, K. Ondrias, A.R. Marks, Intracellular calcium release channel expression during embryogenesis, Dev Biol, 206 (1999) 163-177.

[18] M.B. Ferrari, N.C. Spitzer, Calcium signaling in the developing Xenopus myotome, Dev Biol, 213 (1999) 269-282.

[19] M.B. Ferrari, J. Rohrbough, N.C. Spitzer, Spontaneous calcium transients regulate myofibrillogenesis in embryonic Xenopus myocytes, Dev Biol, 178 (1996) 484-497. [20] M.B. Ferrari, K. Ribbeck, D.J. Hagler, N.C. Spitzer, A calcium signaling cascade essential for myosin thick filament assembly in Xenopus myocytes, The Journal of cell biology, 141 (1998) 1349-1356.

[21] E. Zvaritch, F. Depreux, N. Kraeva, R.E. Loy, S.A. Goonasekera, S. Boncompagni, A. Kraev, A.O. Gramolini, R.T. Dirksen, C. Franzini-Armstrong, C.E. Seidman, J.G. Seidman, D.H. Maclennan, An Ryr1I4895T mutation abolishes Ca2+ release channel function and delays development in homozygous offspring of a mutant mouse line, Proceedings of the National Academy of Sciences of the United States of America, 104 (2007) 18537-18542.

[22] S. Konig, A. Beguet, C.R. Bader, L. Bernheim, The calcineurin pathway links hyperpolarization (Kir2.1)-induced $\mathrm{Ca} 2+$ signals to human myoblast differentiation and fusion, Development, 133 (2006) 3107-3114.

[23] S. Konig, V. Hinard, S. Arnaudeau, N. Holzer, G. Potter, C.R. Bader, L. Bernheim, Membrane hyperpolarization triggers myogenin and myocyte enhancer factor-2 expression during human myoblast differentiation, The Journal of biological chemistry, 279 (2004) 28187-28196.

[24] J.H. Liu, S. Konig, M. Michel, S. Arnaudeau, J. Fischer-Lougheed, C.R. Bader, L. Bernheim, Acceleration of human myoblast fusion by depolarization: graded $\mathrm{Ca} 2+$ signals involved, Development, 130 (2003) 3437-3446.

[25] N.R. Campbell, S.P. Podugu, M.B. Ferrari, Spatiotemporal characterization of short versus long duration calcium transients in embryonic muscle and their role in myofibrillogenesis, Dev Biol, 292 (2006) 253-264.

[26] M. Seth, T. Li, V. Graham, J. Burch, E. Finch, J.A. Stiber, P.B. Rosenberg, Dynamic regulation of sarcoplasmic reticulum $\mathrm{Ca}(2+)$ stores by stromal interaction molecule 1 and sarcolipin during muscle differentiation, Dev Dyn, 241 (2012) 639-647.

[27] J. Stiber, A. Hawkins, Z.S. Zhang, S. Wang, J. Burch, V. Graham, C.C. Ward, M. Seth, E. Finch, N. Malouf, R.S. Williams, J.P. Eu, P. Rosenberg, STIM1 signalling controls store-operated calcium entry required for development and contractile function in skeletal muscle, Nature cell biology, 10 (2008) 688-697.

[28] M. Louis, N. Zanou, M. Van Schoor, P. Gailly, TRPC1 regulates skeletal myoblast migration and differentiation, Journal of cell science, 121 (2008) 3951-3959.

[29] L. Formigli, C. Sassoli, R. Squecco, F. Bini, M. Martinesi, F. Chellini, G. Luciani, F. Sbrana, S. Zecchi-Orlandini, F. Francini, E. Meacci, Regulation of transient receptor potential canonical channel 1 (TRPC1) by sphingosine 1-phosphate in C2C12 myoblasts and its relevance for a role of mechanotransduction in skeletal muscle differentiation, Journal of cell science, 122 (2009) 1322-1333.

[30] J. Lu, T.A. McKinsey, R.L. Nicol, E.N. Olson, Signal-dependent activation of the MEF2 transcription factor by dissociation from histone deacetylases, Proceedings of the National Academy of Sciences of the United States of America, 97 (2000) 4070-4075. 
[31] J. Lu, T.A. McKinsey, C.L. Zhang, E.N. Olson, Regulation of skeletal myogenesis by association of the MEF2 transcription factor with class II histone deacetylases, Molecular cell, 6 (2000) 233-244.

[32] E.A. Miska, C. Karlsson, E. Langley, S.J. Nielsen, J. Pines, T. Kouzarides, HDAC4 deacetylase associates with and represses the MEF2 transcription factor, The EMBO journal, 18 (1999) 5099-5107.

[33] D.B. Sparrow, E.A. Miska, E. Langley, S. Reynaud-Deonauth, S. Kotecha, N. Towers, G. Spohr, T. Kouzarides, T.J. Mohun, MEF-2 function is modified by a novel co-repressor, MITR, The EMBO journal, 18 (1999) 5085-5098.

[34] T.A. McKinsey, C.L. Zhang, J. Lu, E.N. Olson, Signal-dependent nuclear export of a histone deacetylase regulates muscle differentiation, Nature, 408 (2000) 106-111.

[35] B.B. Friday, P.O. Mitchell, K.M. Kegley, G.K. Pavlath, Calcineurin initiates skeletal muscle differentiation by activating MEF2 and MyoD, Differentiation; research in biological diversity, 71 (2003) 217-227.

[36] B.B. Friday, V. Horsley, G.K. Pavlath, Calcineurin activity is required for the initiation of skeletal muscle differentiation, The Journal of cell biology, 149 (2000) 657666.

[37] K.L. Abbott, B.B. Friday, D. Thaloor, T.J. Murphy, G.K. Pavlath, Activation and cellular localization of the cyclosporine A-sensitive transcription factor NF-AT in skeletal muscle cells, Molecular biology of the cell, 9 (1998) 2905-2916.

[38] K. Gajewski, J. Wang, J.D. Molkentin, E.H. Chen, E.N. Olson, R.A. Schulz, Requirement of the calcineurin subunit gene canB2 for indirect flight muscle formation in Drosophila, Proceedings of the National Academy of Sciences of the United States of America, 100 (2003) 1040-1045.

[39] E.R. Chin, E.N. Olson, J.A. Richardson, Q. Yang, C. Humphries, J.M. Shelton, H. Wu, W. Zhu, R. Bassel-Duby, R.S. Williams, A calcineurin-dependent transcriptional pathway controls skeletal muscle fiber type, Genes \& development, 12 (1998) 24992509.

[40] X. Bigard, H. Sanchez, J. Zoll, P. Mateo, V. Rousseau, V. Veksler, R. VenturaClapier, Calcineurin Co-regulates contractile and metabolic components of slow muscle phenotype, The Journal of biological chemistry, 275 (2000) 19653-19660.

[41] U. Delling, J. Tureckova, H.W. Lim, L.J. De Windt, P. Rotwein, J.D. Molkentin, A calcineurin-NFATc3-dependent pathway regulates skeletal muscle differentiation and slow myosin heavy-chain expression, Molecular and cellular biology, 20 (2000) 66006611.

[42] F.J. Naya, B. Mercer, J. Shelton, J.A. Richardson, R.S. Williams, E.N. Olson, Stimulation of slow skeletal muscle fiber gene expression by calcineurin in vivo, The Journal of biological chemistry, 275 (2000) 4545-4548.

[43] S. Schiaffino, A. Serrano, Calcineurin signaling and neural control of skeletal muscle fiber type and size, Trends in pharmacological sciences, 23 (2002) 569-575. [44] R.A. Schulz, K.E. Yutzey, Calcineurin signaling and NFAT activation in cardiovascular and skeletal muscle development, Dev Biol, 266 (2004) 1-16. [45] B.B. Friday, G.K. Pavlath, A calcineurin- and NFAT-dependent pathway regulates Myf5 gene expression in skeletal muscle reserve cells, Journal of cell science, 114 (2001) 303-310. 
[46] K.M. Kegley, J. Gephart, G.L. Warren, G.K. Pavlath, Altered primary myogenesis in NFATC3(-/-) mice leads to decreased muscle size in the adult, Dev Biol, 232 (2001) 115126.

[47] V. Horsley, B.B. Friday, S. Matteson, K.M. Kegley, J. Gephart, G.K. Pavlath, Regulation of the growth of multinucleated muscle cells by an NFATC2-dependent pathway, The Journal of cell biology, 153 (2001) 329-338.

[48] V. Horsley, K.M. Jansen, S.T. Mills, G.K. Pavlath, IL-4 acts as a myoblast recruitment factor during mammalian muscle growth, Cell, 113 (2003) 483-494. [49] A.M. Bennett, N.K. Tonks, Regulation of distinct stages of skeletal muscle differentiation by mitogen-activated protein kinases, Science, 278 (1997) 1288-1291. [50] A. Zetser, D. Frank, E. Bengal, MAP kinase converts MyoD into an instructive muscle differentiation factor in Xenopus, Dev Biol, 240 (2001) 168-181.

[51] A. Zetser, E. Gredinger, E. Bengal, p38 mitogen-activated protein kinase pathway promotes skeletal muscle differentiation. Participation of the Mef2c transcription factor, The Journal of biological chemistry, 274 (1999) 5193-5200.

[52] N. Agell, O. Bachs, N. Rocamora, P. Villalonga, Modulation of the Ras/Raf/MEK/ERK pathway by $\mathrm{Ca}(2+)$, and calmodulin, Cellular signalling, 14 (2002) 649-654.

[53] I. Swapna, L.N. Borodinsky, Interplay between electrical activity and bone morphogenetic protein signaling regulates spinal neuron differentiation, Proceedings of the National Academy of Sciences of the United States of America, 109 (2012) 1633616341.

[54] A. Kumar, N. Khandelwal, R. Malya, M.B. Reid, A.M. Boriek, Loss of dystrophin causes aberrant mechanotransduction in skeletal muscle fibers, FASEB J, 18 (2004) 102113.

[55] R.A. Frost, C.H. Lang, Protein kinase B/Akt: a nexus of growth factor and cytokine signaling in determining muscle mass, J Appl Physiol (1985), 103 (2007) 378-387. [56] D.J. Glass, Skeletal muscle hypertrophy and atrophy signaling pathways, The international journal of biochemistry \& cell biology, 37 (2005) 1974-1984.

[57] C. Rommel, S.C. Bodine, B.A. Clarke, R. Rossman, L. Nunez, T.N. Stitt, G.D. Yancopoulos, D.J. Glass, Mediation of IGF-1-induced skeletal myotube hypertrophy by PI(3)K/Akt/mTOR and PI(3)K/Akt/GSK3 pathways, Nature cell biology, 3 (2001) 10091013.

[58] R.J. Talmadge, J.S. Otis, M.R. Rittler, N.D. Garcia, S.R. Spencer, S.J. Lees, F.J. Naya, Calcineurin activation influences muscle phenotype in a muscle-specific fashion, BMC cell biology, 5 (2004) 28.

[59] S.A. Parsons, B.J. Wilkins, O.F. Bueno, J.D. Molkentin, Altered skeletal muscle phenotypes in calcineurin Aalpha and Abeta gene-targeted mice, Molecular and cellular biology, 23 (2003) 4331-4343.

[60] M. Oh, Rybkin, II, V. Copeland, M.P. Czubryt, J.M. Shelton, E. van Rooij, J.A. Richardson, J.A. Hill, L.J. De Windt, R. Bassel-Duby, E.N. Olson, B.A. Rothermel, Calcineurin is necessary for the maintenance but not embryonic development of slow muscle fibers, Molecular and cellular biology, 25 (2005) 6629-6638.

[61] S.A. Parsons, D.P. Millay, B.J. Wilkins, O.F. Bueno, G.L. Tsika, J.R. Neilson, C.M. Liberatore, K.E. Yutzey, G.R. Crabtree, R.W. Tsika, J.D. Molkentin, Genetic loss of 
calcineurin blocks mechanical overload-induced skeletal muscle fiber type switching but not hypertrophy, The Journal of biological chemistry, 279 (2004) 26192-26200.

[62] J.D. Bruton, A. Katz, H. Westerblad, Insulin increases near-membrane but not global $\mathrm{Ca} 2+$ in isolated skeletal muscle, Proceedings of the National Academy of Sciences of the United States of America, 96 (1999) 3281-3286.

[63] A. Contreras-Ferrat, S. Lavandero, E. Jaimovich, A. Klip, Calcium signaling in insulin action on striated muscle, Cell calcium, 56 (2014) 390-396.

[64] A. Espinosa, M. Estrada, E. Jaimovich, IGF-I and insulin induce different intracellular calcium signals in skeletal muscle cells, The Journal of endocrinology, 182 (2004) 339-352.

[65] V. Horsley, G.K. Pavlath, Prostaglandin F2(alpha) stimulates growth of skeletal muscle cells via an NFATC2-dependent pathway, The Journal of cell biology, 161 (2003) 111-118.

[66] L. Formigli, E. Meacci, C. Sassoli, R. Squecco, D. Nosi, F. Chellini, F. Naro, F. Francini, S. Zecchi-Orlandini, Cytoskeleton/stretch-activated ion channel interaction regulates myogenic differentiation of skeletal myoblasts, J Cell Physiol, 211 (2007) 296306.

[67] M. Hara, K. Tabata, T. Suzuki, M.K. Do, W. Mizunoya, M. Nakamura, S. Nishimura, S. Tabata, Y. Ikeuchi, K. Sunagawa, J.E. Anderson, R.E. Allen, R. Tatsumi, Calcium influx through a possible coupling of cation channels impacts skeletal muscle satellite cell activation in response to mechanical stretch, American journal of physiology. Cell physiology, 302 (2012) C1741-1750.

[68] T.J. Burkholder, Stretch-induced ERK2 phosphorylation requires PLA2 activity in skeletal myotubes, Biochemical and biophysical research communications, 386 (2009) 60-64.

[69] M.A. Carrasco, N. Riveros, J. Rios, M. Muller, F. Torres, J. Pineda, S. Lantadilla, E. Jaimovich, Depolarization-induced slow calcium transients activate early genes in skeletal muscle cells, American journal of physiology. Cell physiology, 284 (2003) C1438-1447.

[70] K. Ellwanger, C. Kienzle, S. Lutz, Z.G. Jin, M.T. Wiekowski, K. Pfizenmaier, A. Hausser, Protein kinase D controls voluntary-running-induced skeletal muscle remodelling, The Biochemical journal, 440 (2011) 327-324.

[71] M.S. Kim, J. Fielitz, J. McAnally, J.M. Shelton, D.D. Lemon, T.A. McKinsey, J.A. Richardson, R. Bassel-Duby, E.N. Olson, Protein kinase D1 stimulates MEF2 activity in skeletal muscle and enhances muscle performance, Molecular and cellular biology, 28 (2008) 3600-3609.

[72] C.A. Steelman, J.C. Recknor, D. Nettleton, J.M. Reecy, Transcriptional profiling of myostatin-knockout mice implicates Wnt signaling in postnatal skeletal muscle growth and hypertrophy, FASEB J, 20 (2006) 580-582.

[73] D. Bodnar, N. Geyer, O. Ruzsnavszky, T. Olah, B. Hegyi, M. Sztretye, J. Fodor, B. Dienes, A. Balogh, Z. Papp, L. Szabo, G. Muller, L. Csernoch, P. Szentesi, Hypermuscular mice with mutation in the myostatin gene display altered calcium signalling, The Journal of physiology, 592 (2014) 1353-1365.

[74] L. Wei-Lapierre, E.M. Carrell, S. Boncompagni, F. Protasi, R.T. Dirksen, Orai1dependent calcium entry promotes skeletal muscle growth and limits fatigue, Nature communications, 4 (2013) 2805. 
[75] T. Li, E.A. Finch, V. Graham, Z.S. Zhang, J.D. Ding, J. Burch, M. Oh-hora, P. Rosenberg, STIM1-Ca(2+) signaling is required for the hypertrophic growth of skeletal muscle in mice, Molecular and cellular biology, 32 (2012) 3009-3017.

[76] J.L. Ferey, J.J. Brault, C.A. Smith, C.A. Witczak, Constitutive activation of CaMKKalpha signaling is sufficient but not necessary for mTORC1 activation and growth in mouse skeletal muscle, American journal of physiology. Endocrinology and metabolism, 307 (2014) E686-694.

[77] M.G. Klein, H. Cheng, L.F. Santana, Y.H. Jiang, W.J. Lederer, M.F. Schneider, Two mechanisms of quantized calcium release in skeletal muscle, Nature, 379 (1996) 455-458. [78] X. Wang, N. Weisleder, C. Collet, J. Zhou, Y. Chu, Y. Hirata, X. Zhao, Z. Pan, M. Brotto, H. Cheng, J. Ma, Uncontrolled calcium sparks act as a dystrophic signal for mammalian skeletal muscle, Nature cell biology, 7 (2005) 525-530.

[79] N. Weisleder, M. Brotto, S. Komazaki, Z. Pan, X. Zhao, T. Nosek, J. Parness, H. Takeshima, J. Ma, Muscle aging is associated with compromised Ca2+ spark signaling and segregated intracellular Ca2+ release, The Journal of cell biology, 174 (2006) 639645.

[80] X. Zhao, N. Weisleder, A. Thornton, Y. Oppong, R. Campbell, J. Ma, M. Brotto, Compromised store-operated Ca2+ entry in aged skeletal muscle, Aging cell, 7 (2008) 561-568.

[81] J.S. Woo, J.H. Hwang, M. Huang, M.K. Ahn, C.H. Cho, J. Ma, E.H. Lee, Interaction between mitsugumin 29 and TRPC3 participates in regulating $\mathrm{Ca}(2+)$ transients in skeletal muscle, Biochemical and biophysical research communications, 464 (2015) 133 139.

[82] J.S. Woo, H. Kim do, P.D. Allen, E.H. Lee, TRPC3-interacting triadic proteins in skeletal muscle, The Biochemical journal, 411 (2008) 399-405.

[83] Z. Pan, Y. Hirata, R.Y. Nagaraj, J. Zhao, M. Nishi, S.M. Hayek, M.B. Bhat, H. Takeshima, J. Ma, Co-expression of MG29 and ryanodine receptor leads to apoptotic cell death: effect mediated by intracellular Ca2+ release, The Journal of biological chemistry, 279 (2004) 19387-19390.

[84] D.L. Waning, K.S. Mohammad, S. Reiken, W. Xie, D.C. Andersson, S. John, A. Chiechi, L.E. Wright, A. Umanskaya, M. Niewolna, T. Trivedi, S. Charkhzarrin, P. Khatiwada, A. Wronska, A. Haynes, M.S. Benassi, F.A. Witzmann, G. Zhen, X. Wang, X. Cao, G.D. Roodman, A.R. Marks, T.A. Guise, Excess TGF-beta mediates muscle weakness associated with bone metastases in mice, Nature medicine, 21 (2015) 12621271.

[85] Y. Iwata, Y. Katanosaka, Y. Arai, K. Komamura, K. Miyatake, M. Shigekawa, A novel mechanism of myocyte degeneration involving the Ca2+-permeable growth factorregulated channel, The Journal of cell biology, 161 (2003) 957-967.

[86] M.K. Tu, L.N. Borodinsky, Spontaneous calcium transients manifest in the regenerating muscle and are necessary for skeletal muscle replenishment, Cell calcium, 56 (2014) 34-41.

[87] N.A. Dumont, C.F. Bentzinger, M.C. Sincennes, M.A. Rudnicki, Satellite Cells and Skeletal Muscle Regeneration, Comprehensive Physiology, 5 (2015) 1027-1059.

[88] D. Montarras, J. Morgan, C. Collins, F. Relaix, S. Zaffran, A. Cumano, T. Partridge, M. Buckingham, Direct isolation of satellite cells for skeletal muscle regeneration, Science, 309 (2005) 2064-2067. 
[89] F. Antigny, S. Konig, L. Bernheim, M. Frieden, Inositol 1,4,5 trisphosphate receptor 1 is a key player of human myoblast differentiation, Cell calcium, 56 (2014) 513-521. [90] A.G. Oliveira, V.A. Andrade, E.S. Guimaraes, R.M. Florentino, P.A. Sousa, P.E. Marques, F.M. Melo, M.J. Ortega, G.B. Menezes, M.F. Leite, Calcium signalling from the type I inositol 1,4,5-trisphosphate receptor is required at early phase of liver regeneration, Liver Int, 35 (2015) 1162-1171.

[91] T. Tumbar, G. Guasch, V. Greco, C. Blanpain, W.E. Lowry, M. Rendl, E. Fuchs, Defining the epithelial stem cell niche in skin, Science, 303 (2004) 359-363.

[92] C. Blanpain, E. Fuchs, Stem cell plasticity. Plasticity of epithelial stem cells in tissue regeneration, Science, 344 (2014) 1242281.

[93] C. Blanpain, W.E. Lowry, A. Geoghegan, L. Polak, E. Fuchs, Self-renewal, multipotency, and the existence of two cell populations within an epithelial stem cell niche, Cell, 118 (2004) 635-648.

[94] A.B. Lansdown, Calcium: a potential central regulator in wound healing in the skin, Wound Repair Regen, 10 (2002) 271-285.

[95] M. Vandenberghe, M. Raphael, V. Lehen'kyi, D. Gordienko, R. Hastie, T. Oddos, A. Rao, P.G. Hogan, R. Skryma, N. Prevarskaya, ORAI1 calcium channel orchestrates skin homeostasis, Proceedings of the National Academy of Sciences of the United States of America, 110 (2013) E4839-4848.

[96] S. Denda, J. Kumamoto, K. Takei, M. Tsutsumi, H. Aoki, M. Denda, Ryanodine receptors are expressed in epidermal keratinocytes and associated with keratinocyte differentiation and epidermal permeability barrier homeostasis, J Invest Dermatol, 132 (2012) 69-75.

[97] Y. Liu, M.F. Schneider, FGF2 activates TRPC and $\mathrm{Ca}(2+)$ signaling leading to satellite cell activation, Frontiers in physiology, 5 (2014) 38.

[98] K. Sakuma, J. Nishikawa, R. Nakao, K. Watanabe, T. Totsuka, H. Nakano, M. Sano, M. Yasuhara, Calcineurin is a potent regulator for skeletal muscle regeneration by association with NFATc1 and GATA-2, Acta neuropathologica, 105 (2003) 271-280. [99] N. Stupka, J.D. Schertzer, R. Bassel-Duby, E.N. Olson, G.S. Lynch, Calcineurin-A alpha activation enhances the structure and function of regenerating muscles after myotoxic injury, American journal of physiology. Regulatory, integrative and comparative physiology, 293 (2007) R686-694.

[100] R.B. Vega, R. Bassel-Duby, E.N. Olson, Control of cardiac growth and function by calcineurin signaling, The Journal of biological chemistry, 278 (2003) 36981-36984.

[101] R.B. Vega, B.A. Rothermel, C.J. Weinheimer, A. Kovacs, R.H. Naseem, R. BasselDuby, R.S. Williams, E.N. Olson, Dual roles of modulatory calcineurin-interacting protein 1 in cardiac hypertrophy, Proceedings of the National Academy of Sciences of the United States of America, 100 (2003) 669-674.

[102] O.M. Kielbasa, J.G. Reynolds, C.L. Wu, C.M. Snyder, M.Y. Cho, H. Weiler, S. Kandarian, F.J. Naya, Myospryn is a calcineurin-interacting protein that negatively modulates slow-fiber-type transformation and skeletal muscle regeneration, FASEB J, 25 (2011) 2276-2286.

[103] F. Raynaud, G. Carnac, A. Marcilhac, Y. Benyamin, m-Calpain implication in cell cycle during muscle precursor cell activation, Experimental cell research, 298 (2004) 4857. 
[104] I.M. Conboy, M.J. Conboy, G.M. Smythe, T.A. Rando, Notch-mediated restoration of regenerative potential to aged muscle, Science, 302 (2003) 1575-1577.

[105] A.S. Brack, I.M. Conboy, M.J. Conboy, J. Shen, T.A. Rando, A temporal switch from notch to Wnt signaling in muscle stem cells is necessary for normal adult myogenesis, Cell stem cell, 2 (2008) 50-59.

[106] A.S. Brack, M.J. Conboy, S. Roy, M. Lee, C.J. Kuo, C. Keller, T.A. Rando, Increased Wnt signaling during aging alters muscle stem cell fate and increases fibrosis, Science, 317 (2007) 807-810.

[107] V.P. Pai, J.M. Lemire, J.F. Pare, G. Lin, Y. Chen, M. Levin, Endogenous gradients of resting potential instructively pattern embryonic neural tissue via Notch signaling and regulation of proliferation, The Journal of neuroscience : the official journal of the Society for Neuroscience, 35 (2015) 4366-4385.

[108] C.M. Freisinger, I. Schneider, T.A. Westfall, D.C. Slusarski, Calcium dynamics integrated into signalling pathways that influence vertebrate axial patterning, Philos Trans R Soc Lond B Biol Sci, 363 (2008) 1377-1385.

[109] R. Nusse, Wnt signaling, Cold Spring Harbor perspectives in biology, 4 (2012). 


\section{Figure legends}

Fig. 1. Cellular mechanisms of skeletal muscle development, homeostasis and regeneration. During embryonic development mesodermal muscle stem cells expressing Pax3/Pax7 transcription factors proliferate and specialize into myogenic progenitors through the expression of the myogenic regulatory factors including Myf5, MyoD and myogenin. Progressive differentiation is followed by sarcomere assembly, spatial arrangement of muscle cells, and their fusion into multinucleated muscle fibers. Muscle growth requires protein synthesis and enlargement of individual fibers, and is triggered during postnatal development and upon exercise or muscle overload. Trophic stimuli can also elicit a switch in muscle fiber type. In contrast, muscle wasting is characteristic of muscle dystrophy and aging. Skeletal muscle regeneration requires activation of muscle satellite cells that recapitulate the myogenic program, repairing and replenishing the injured tissue.

Fig. 2. $\mathrm{Ca}^{2+}$ signaling in skeletal muscle plasticity. $\mathrm{Ca}^{2+}$ activity in muscle cells at different maturational states leads to recruitment of $\mathrm{Ca}^{2+}$-dependent kinases and phosphatases triggering diverse cellular responses required for myogenesis, muscle homeostasis and regeneration. 
development

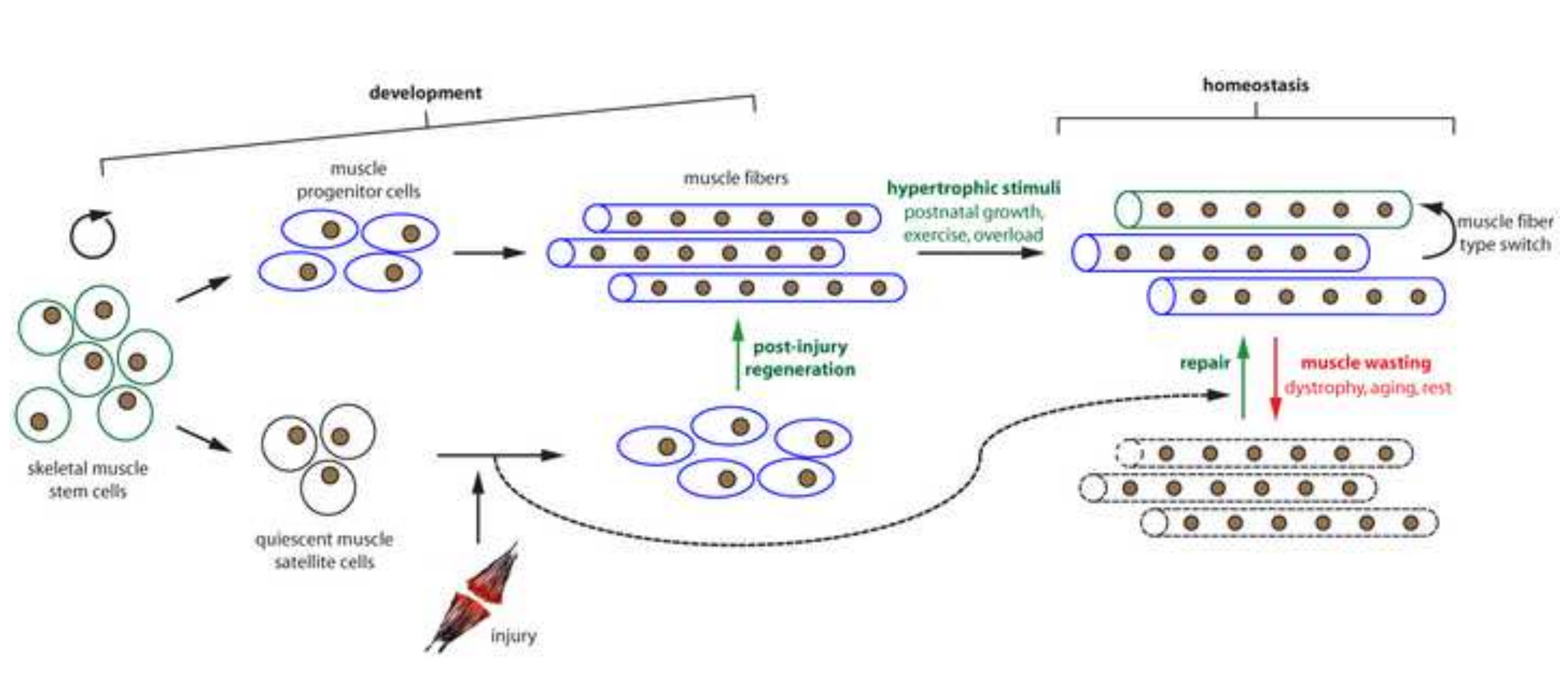


TRP

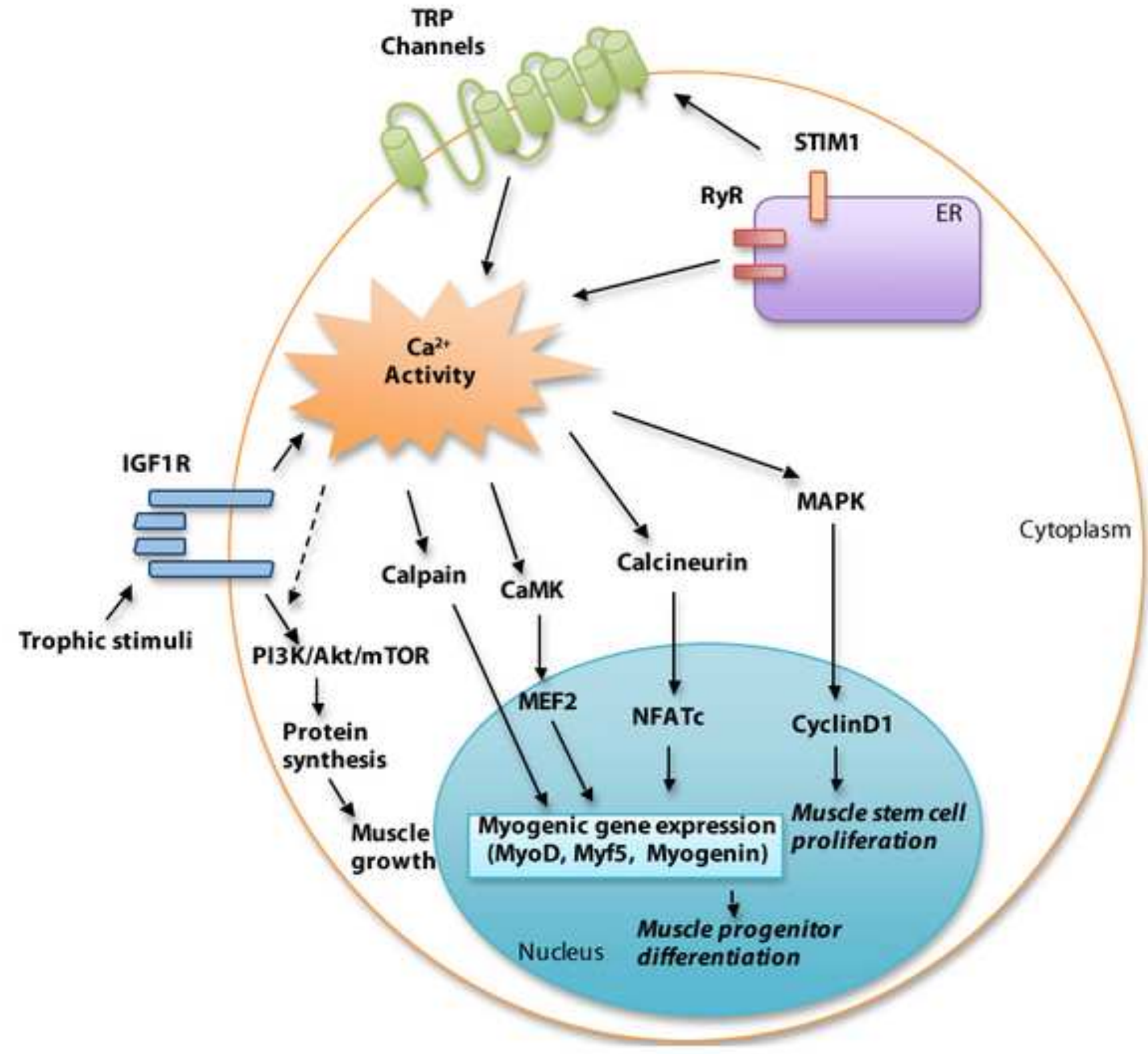


SKELETAL MUSCLE

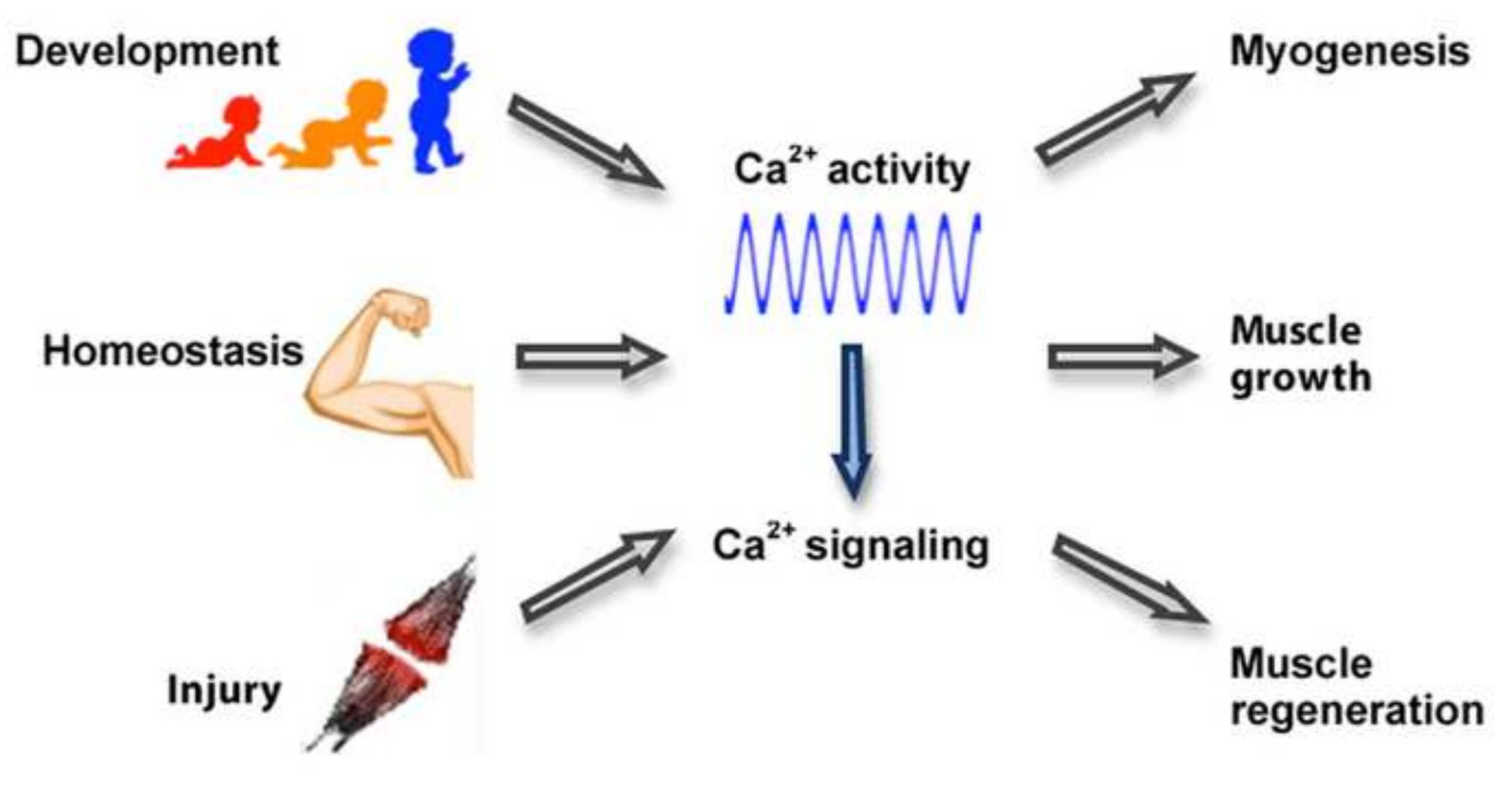

(1)

SKELETAL MUSCLE

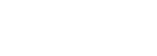
regeneratio

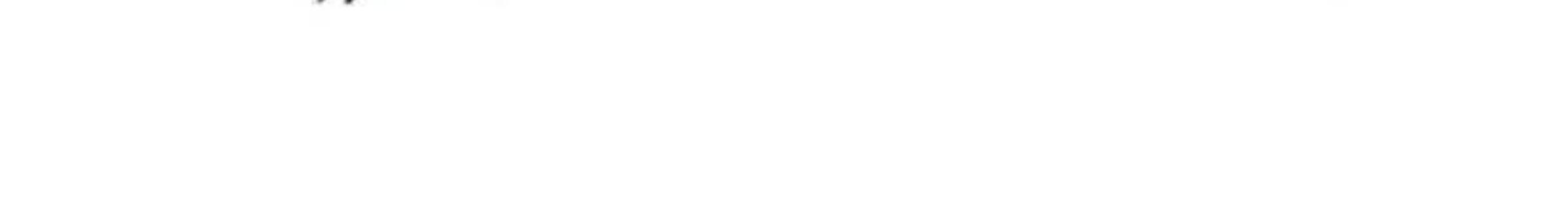

